Short Report

\title{
Childhood Adversity and Depression among Older Adults: Results from a Longitudinal Survey in China
}

\author{
Yue Li $1{ }^{*}$ and Jiehua $\mathrm{Lu}^{2}$ \\ 1 China Population and Development Research Center, Haidian district, Beijing, China \\ 2 Peking University, Haidian district, Beijing, China
}

Received September 20, 2018; Accepted January 08; 2019

\begin{abstract}
This study examined the association of childhood adversity with depression or severity of depressive symptoms among Chinese older adults, using data from the China Health and Retirement Longitudinal Study (CHARLS). The data is from a nationally representative sample of Chinese residents aged 45 or older and surveys of the sample population were conducted in 2011 and 2013; and individuals aged at 60 years or older, and interviewed for depressive symptom were included in this study. Multiple logistic regression analyses showed that the likelihood of depression was significantly associated with poor parental mental status, physical abuse, and emotional abuse during childhood. Our study adds to research in the area of adverse childhood events and its effect on adult psychological and physical well-being.
\end{abstract}

\section{KEYWORDS}

Depression; childhood adversity; population aging

\section{INTRODUCTION}

Depression is a common and serious mental health problem in the general population and affects about $4-15 \%$ of older adults [1]. According to the estimates of the World Health Organization in 2017, depression is more prevalent in the general population of North America. The United States 2012-2013 National Survey estimated that the 12-month and lifetime prevalence of depression was $10.45 \%$ and $20.6 \%$, respectively [2]. While the prevalence of depression is estimated to be lower in Asian countries, the lifetime prevalence of suicide attempts in patients with depression could be as high as $40 \%$ [3]. Meanwhile, depression symptoms in older adults are often mistaken for other symptoms of normal aging and so do not draw attention clinically, and patients do not get treatment.

Studies have indicated that childhood adversity experience is not only associated with risk of suicide [4] and risky behaviors such as alcohol misuse, risky sexual practices and criminal activities which persist into adulthoood [5], but also with geriatric depression in later life [6]. Greater psycho-social adversity in childhood has been associated with poorer physical capability in people of middle age in Western societies [7]. Recently, a cohort study has indicated that low childhood socioeconomic status is associated with the onset of depression in Japanese older adults [8]; childhood abuse has been associated with depression in later life in older persons in The
Netherlands [9]. In this Dutch study, the investigators suggested that older adults with a history of childhood abuse may be more negatively affected by stress or stressful events, and presented data which suggested the dysregulation of the hypothalamic-pituitary-adrenal (HPA) axis [9]. In addition, the causes of depression in older aduIts are not clear, and study of childhood adversity may help elucidate the etiology of depression in older adults. Since no study has been conducted in the Chinese populations, we performed a study to examine the effect of childhood adversity on depression symptoms and depression score among the elderly.

\section{DATA AND METHODS}

This study used the datasets from surveys conducted in 2011 and 2013 as a part of the China Health and Retirement Longitudinal Study (CHARLS) [10]. The sample included Chinese residents aged 60 years or older who were interviewed as part of a nationally representative sample of Chinese residents; and individuals who participated in the interviews conducted in both 2011 and 2013 were included for this study.

The depression outcome was measured using the Center for Epidemiologic Studies Depression 10-item (CES-D10) scale, a short self-report scale designed to measure depressive symptomatology in the general population [11]. Depression was defined when the total CES-D10 score was greater than 10 and the total score of depression

* Correspondence: Yue Li, Email:liyuefeiyang@126.com 
was obtained. The childhood adversities were measured by five domains: physical abuse, emotional abuse, emotional neglect, the worse mental status of parents or guardian, and a negative relationship of parents. Because the sample was with a repeated-measure in both 2011 and 2013, we performed, after a descriptive analysis of depression by the childhood adversity, a multiple logistic regression analysis and a multiple linear regression with random-effect model to examine the association of the risk for depression and depressive symptom score with the childhood adversity, respectively, in individuals who were interviewed in the surveys at both years.

\section{RESULTS}

The baseline statistics of individual child hood adversity measurement and coding are presented and score was summarized by individual domains (Table 1). Depression and the mean depression score were increased with multiple domains of childhood adversity experienced. Based on data from 2011, the rate of depression was significantly elevated in individual older adults who experienced poor mental status of parents or guardians, such as guardians who often felt nervous and anxious (47.64\%), guardians who often got upset easily or feel panicky (50.97\%), guardians who showed sadness or depression lasting over two weeks $(46.35 \%)$ compared with those who did not have these respective experiences $(P<0.0001)$. Individuals who experienced physical abuse such as being beaten by the guardian $(40.8 \%)$ and emotional abuse such as the guardian being too strict $(40.5 \%)$ in childhood also had a significantly elevated rate of depression in later adult life compared those who did not have such experiences $(P<0.0001)$ (Table 2$)$.

While the rate of depression was a little lower, the findings were consistently present in the follow-up survey conducted in 2013. Individuals who experienced a childhood adversity were more likely to have depression in 2013 when the follow-up survey was conducted. These associations of childhood adversity with depression in later life were also consistent when the total score of depression was analyzed in both 2011 and 2013.

After adjusting for covariates such as age, sexes, as well as other variables that measure physical condition, multiple domains of childhood adversity experience were associated with the rate of depression and total score of depression in the combined analysis of the two surveys together. Multiple logistic regression analysis of depression in both surveys (2011 and 2013) found that the likelihood of depression was significantly associated with poor parental mental status (OR=1.44; 95\% CL: 1.311.57), physical abuse (OR=1.35; 95\% CL: 1.12-1.65), and emotional abuse (OR=1.23; 95\% CL: 1.04-1.46) (Table 3). In addition, we found that the poor parental mental health status during childhood was associated with depression symptom scores in later life (Beta $=1.14$; 95\% CL: 0.95-1.33); and it was still significant even after adjusting for the confounding factors (Beta $=0.87$; 95\% CL: $0.71-1.04)$. Further, the number of total adverse events experienced in childhood significantly increased the likelihood; and this may suggest a "dose-response" relationship between childhood adversity and depression in later life.

Table 1. Descriptive statistics and coding for the independent variables at the baseline in $2011(n=3,436)$.

\begin{tabular}{|c|c|c|c|}
\hline Variable & Code & $\%$ & Mean (SD) \\
\hline Poor mental status of parents or guardian & Sum score & & $0.55(0.90)$ \\
\hline Guardians often felt nervous and anxious & $\begin{array}{l}1, \text { most, often or always } \\
0, \text { No or selfdom }\end{array}$ & 18.51 & \\
\hline Guardians often got upset easily or feel panicky & $\begin{array}{l}1 \text {, most, often or always } \\
0, \text { No or selfdom }\end{array}$ & 15.02 & \\
\hline Guardians' sadness or depression lasting over 2 weeks & $\begin{array}{l}1 \text {, Yes } \\
0 \text {, No }\end{array}$ & 21.54 & \\
\hline Physical abuse & Sum score & & $0.26(0.44)$ \\
\hline Beaten by guardians & $\begin{array}{l}1=\text { often or sometime } \\
0=\text { seldom or never }\end{array}$ & 25.87 & \\
\hline Emotional abuse & Sum score & & $0.33(0.50)$ \\
\hline Guardians were too strict & $\begin{array}{l}1, \text { strict or too strict } \\
0, \text { no or little strict }\end{array}$ & 33.41 & \\
\hline Guardians treat siblings better than you & $\begin{array}{l}1 \text {, Yes } \\
0, \text { no }\end{array}$ & 1.46 & \\
\hline Emotional neglect & Sum score & & $0.44(0.68)$ \\
\hline Female guardian often gave love and affection & $\begin{array}{l}1, \text { No or selfdom } \\
0, \text { Sometimes or often }\end{array}$ & 21.21 & \\
\hline Female guardian often into watching over you & $\begin{array}{l}1, \text { No or selfdom } \\
0, \text { Sometimes or often }\end{array}$ & 23.52 & \\
\hline Poor parental relationship & Sum score & & $0.28(0.60)$ \\
\hline Parents often quarrel & $\begin{array}{l}\text { 1, Sometime or often } \\
0 \text {, few or never }\end{array}$ & 19.70 & \\
\hline Your father often beat up your mother & $\begin{array}{l}1 \text {, Sometime or often } \\
0 \text {, few or never }\end{array}$ & 7.67 & \\
\hline Your mother often beat up your father & $\begin{array}{l}1 \text {, Sometime or often } \\
0 \text {, few or never }\end{array}$ & 1.17 & \\
\hline
\end{tabular}




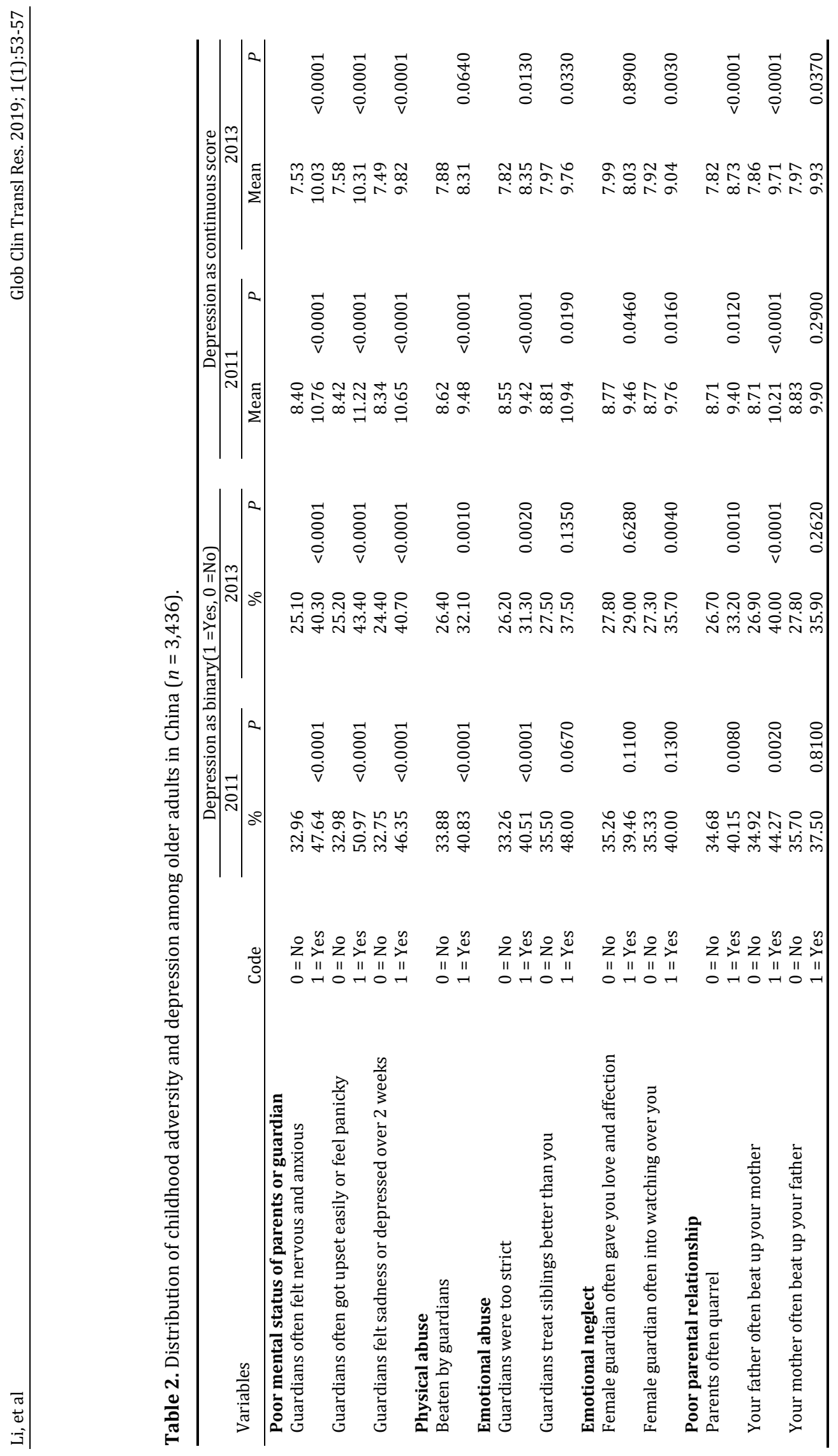


Table 3. Multiple regression with a random-effect model estimates of childhood adversity on depression in older adults (age $\geq 60$ years).

\begin{tabular}{|c|c|c|c|c|c|c|c|c|c|c|c|c|}
\hline & \multicolumn{5}{|c|}{ Depression as a binary } & & \multicolumn{6}{|c|}{ Depressive score } \\
\hline & \multicolumn{2}{|c|}{ Model 1} & & \multicolumn{2}{|r|}{ Model 2} & & \multicolumn{2}{|c|}{ Model 1} & & \multicolumn{2}{|r|}{ Model 2} & \\
\hline & OR & $95 \%$ CL & & OR & $95 \% \mathrm{CL}$ & & Beta & $95 \% \mathrm{CL}$ & & Beta & $95 \%$ CL & \\
\hline Physical abuse & 1.43 & $(1.16,1.77)$ & $* * *$ & 1.35 & $(1.12,1.65)$ & $* *$ & 0.44 & $(0.03,0.84)$ & $*$ & 0.24 & $(-0.11,0.58)$ & \\
\hline Emotional abuse & 1.32 & $(1.11,1.58)$ & $* *$ & 1.23 & $(1.04,1.46)$ & * & 0.44 & $(0.09,0.78)$ & * & 0.27 & $(-0.03,0.57)$ & \\
\hline Emotional neglect & 1.21 & $(1.01,1.46)$ & $*$ & 1.08 & $(0.90,1.30)$ & & 0.44 & $(0.08,0.81)$ & $*$ & 0.25 & $(-0.06,0.57)$ & \\
\hline Poor parental mental status & 1.59 & $(1.43,1.75)$ & $* * *$ & 1.44 & $(1.31,1.57)$ & $* * *$ & 1.14 & $(0.95,1.33)$ & $* * *$ & 0.87 & $(0.71,1.04)$ & $* * *$ \\
\hline Poor parental relationship & 1.15 & $(0.99,1.34)$ & & 1.09 & $(0.95,1.26)$ & & 0.33 & $(0.03,0.62)$ & * & 0.21 & $(-0.04,0.46)$ & \\
\hline
\end{tabular}

${ }^{* * *} P<0.001,{ }^{* *} P<0.01,{ }^{*} P<0.05$; Model 1, Controlling for age, sex, marital status, resident; Model 2, Adjusting for additional physical status, such as living with children, Instrumental activities of daily living (IADL), number of chronic illness, cognitive status, memory, sleep, type of medical insurance, community condition, education and previous occupation before retirement.

\section{DISCUSSIONS}

Our findings provide novel evidence that childhood adverse events affect the likelihood of depression and levels of depressive symptom scores in later life in the Chinese population which is consistent with previous studies in older adults $[8,9]$ in other global regions. Previous studies have indicated that childhood adversity interacted with past year stressful life events on the 12-month prevalence of major depression, post-traumatic stress disorder and anxiety disorder [12] in general populations based on the National Epidemiological Survey of Alcohol and Relate Conditions. Individuals with 3 or more childhood adverse events may have a 2 -fold increase in the risk of developing depression when experiencing stressful events during the past year compared to those without suffering from the childhood adverse events. In addition, a large meta-analysis of 18 case-control studies, 10 prospective studies and 8 population-based studies demonstrated a consistent association with moderate to high effect size of childhood adversity with psychosis [13].

In summary, using a population-based longitudinal survey in older adults, we found evidence that childhood adversity significantly increased the likelihood of depression in later life in residents of China. Mental health is essential not only for child development but also for health in later life. One limitation of our study is that we did not have objective data on these childhood adverse events but relied on recall of people in the survey, and it is likely that people currently experiencing depression will be more likely to remember adverse childhood events than people who are not depressed. Even with this potential bias, our study adds to research in the area of adverse childhood events and its effect on adult psychological and physical well-being. Further research is needed to find interventions that can be translated into real life moderation of childhood adverse effects on subsequent adult well-being.

\section{CONFLICTS OF INTEREST}

The authors declare that there is no conflict of interest regarding the publication of this paper.

\section{ACKNOWLEDGMENTS}

This study is supported by key projects of Humanities and Social Sciences Key Base of Ministry of Education (16JDD840004) and China National Natural Science Foundation's grants (71490732).

\section{REFERENCES}

1. Subramaniam M, Abdin E, Sambasivam R, Vaing-ankar JA, Picco L, Pang S. Prevalence of depression among older adults - results from the well-being of the Singapore elderly study. Ann Acad Med Singapore. 2016; 45:123-133.

2. Hasin DS, Sarvet AL, Meyers JL, Saha TD, Ruan WJ, Stohl M. Epidemiology of Adult DSM-5 Major depressive disorder and its decifiers in the United States. JAMA Psychiatry. 2018; 75:336-346.

3. Dong M, Wang SB, Li Y, Xu DD, Ungvari GS, Ng CH. Prevalence of suicidal behaviors in patients with major depressive disorder in China: A comprehensive meta-analysis. J Affect Disord. 2018; 225: 32-39.

4. Bjorkenstam C, Björkenstam C, Kosidou K, Björkenstam E. Childhood adversity and risk of suicide: cohort study of 548,721 adolescents and young adults in Sweden. BMJ. 2017; 357:j1334.

5. Gilbert R, Widom CS, Browne K, Fergusson D, Webb E, Janson S. Burden and consequences of child maltreatment in high-income countries. Lancet. 2009; 373:68-81.

6. Ege MA, Messias E, Thapa PB, Krain LP. Adverse childhood experiences and geriatric depression: results from the 2010 BRFSS. Am J Geriatr Psychiatry. 2015; 23:110-114.

7. Das-Munshi J1, Clark C, Dewey ME, Leavey G, Stansfeld SA, Prince MJ. Does childhood adversity account for poorer 
mental and physical health in second-generation Irish people living in Britain? Birth cohort study from Britain (NCDS). BMJ Open. 2013 Mar 1; 3(3):e001335. doi: 10.1136 /bmjopen-2012- 001335.

8. Tani Y, Fujiwara T, Kondo N, Noma H, Sasaki Y, Kondo K. Childhood Socioeconomic Status and Onset of depression among Japanese older adults: The JAGES Prospective Cohort Study. Am J Geriatr Psychiatry. 2016; 24:717-26.

9. Wielaard I, Schaakxs R, Comijs HC, Stek ML, Rhe-bergen D. The influence of childhood abuse on cortisol levels and the cortisol awakening response in depressed and nondepressed older adults. World J Biol Psychiatry. 2018; 19:440449.

10. Zhao Y, Hu Y, Smith JP, Strauss J, Yang G. Cohort profile: the China Health and Retirement Longitudinal Study (CHARLS). Int J Epidemiol. 2014; 43: 61-68.
11. Andresen EM, Byers K, Friary J, Kosloski K, Montgomery R. performance of the 10-item Center for Epidemiologic Studies Depression scale for caregiving research. SAGE Open Med. 2013; 1: 2050312113514576.

12. McLaughlin KA, Conron KJ, Koenen KC, Gilman SE. Childhood adversity, adult stressful life events, and risk of pastyear psychiatric disorder: a test of the stress sensitization hypothesis in a population-based sample of adults. Psychol Med. 2010; 40: 1647-1658.

13. Varese F, Smeets F, Drukker M, Lieverse R, Lataster T, Viechtbauer W. Childhood adversities increase the risk of psychosis: a meta-analysis of patient- control, prospectiveand cross-sectional cohort studies. Schizophr Bull. 2012; 38:661-671.

How to cite this article:

Li Y, Lu J. Childhood adversity and depression among older adults: evidence from a longitudinal survey in China. Glob Clin Transl Res. 2019; 1 (1):53-57.

Copyright (c) 2019 by the Global Clinical and Translational Research. 